Journal of Sustainability Perspectives

\title{
Conservation Initiatives/Practices at Universities
}

\author{
Syeda Eeman Zahra Bokhari ${ }^{1, *}$, Syeda Marriam Bakhtiar ${ }^{2}$, Saira Ahmed \\ ${ }^{1,2,3}$ Capital University of Science \& Technology, Islamabad Expressway, Kahuta Road, Zone-V Islamabad. \\ *corresponding author: e.bokhari98@gmail.com
}

\section{Article Info}

Received:

15 March 2021

Accepted:

25 May 2021

Published:

1 June 2021

DOI:

https://doi.org/10.14710

Lisp.2021.11752

\begin{abstract}
Growing actions on putting into practice the policy for improving sustainable development gives universities great variety of opportunities on implementation of different 'green' technologies in their campuses. Campus greening is the first step towards sustainability. The purpose of this article is to present existing approaches on the categories of sustainable campus initiatives, their significance for complete region development and the state of the environment. On the example of the inner garden of Volgograd State University, the authors describe the importance of greening the external campus sites for minimization of the negative environmental and health affects for students and faculty staff. The green initiative reflects the institution's function as center of technological and social regional development. The green garden can reduce stress and also provide an esthetic sense by involving attractive surroundings. The impact of climatic zone on emerging of appropriate management and maintenance systems, meaningful comparison with the past landscape solutions are also reviewed in the present article. By implementing green technologies, the university shows its prudence and readiness to behave responsibly, sensibly and maturely in response to sustainability issues of the present and the future.
\end{abstract}

\section{Keyword:}

green campus, green technologies, sustainability, green campus affect, eco-friendly community.

\section{Introduction}

The variations, variety or differences in certain aspects or qualities is termed as diversity, thus biodiversity can be understood as the variations among the living organisms [1]. The term "biodiversity" rather has an elaborated definition or explanation. Currently, biodiversity is defined as the hallmark of a specific geographic location which depicts the variety of living organisms within the areas, their assemblages, communities and processes, and whether they are naturally occurring or altered by the humans [1].

The genetic diversity, identity and quantity of various species, assemblages of species, biotic communities, and biotic processes and their amount (i.e. abundance, biomass, cover, 
rate) and structure provides the measurement criterions of biodiversity. The spatial scale of biodiversity measurement varies from microsites and habitat patches to whole biosphere [1].

The period of greatest biodiversity in the history of the earth, also marks the appearance of human species on the planet earth. From that time till now, as humans expand their civilization, they have been modifying the earth's natural ecosystem all along, and have been horribly impacting biodiversity all along as well, as the lowest level of biodiversity has been marked at the end of the Mesozoic era, 65 million years ago. Ever since then, biodiversity has been reducing, and the impact of it is certainly harmful, which is actually called a "biodiversity crisis" [2].

Material, cultural and biological wealth are the three primary wealth sources of every country. The material and cultural wealth are well understood by everyone since they deal with it on a regular basis, but biological diversity is of a lesser concern to everyone. But this strategy to be, is the most erroneous and will be a regret for every human on earth. The biotic community of a geographical location or a country is the product of the million years of evolution centred on that area, hence it as much of a country's heritage as anything else and should be checked on to that level as well. Moreover, biotic wealth of a country leads to the other two types of wealth as well, as it comprises of the material wealth to be a source of production for food, medicine and other commercially necessary products [2].

\section{Eco-anxiety}

"Eco-anxiety" is one of the most visible impacts of global climate change. This a mental and emotional condition or state of being, caused by having the knowledge of environmental conditions and their detrimental effects. A clearly visible environmental problem may lead to eco-anxiety, but it may also be an indirect effect. This can be understood by the example, that one may feel bad if a forest area or a mountain area around them is destroyed, but they may feel threatened by the horrifying impacts of this cut down on the climate and the impact of the climate change on their future, leading to anxiety [3].

\section{Endemism and Diversity Across Space}

Passing on from a region to another, the composition of the species may vary greatly, though the number of the species might remain the same. The change in the biodiversity is measured by the change in a region, by the change in the species of that region. The variation in specie composition is called as between-area diversity or beta diversity. The hypothesis that two near by areas may contain 10 species each, but the number of the species they share might range from 0 to 10 i.e. highest beta diversity to lowest beta diversity, gives rise to various measures of determining the change in diversity [4].

The species prevalent in a specific area are known to be the endemic species of that area. As one passes from one region to another, if the regions hold greater number of endemic species, one would experience greater between-area diversity. The typical size of a species range is also connected to endemism and between-area diversity. If an area has less typical range of species, then one could pass from an area of one set of species to an area with another set of species, more quickly. The endemism varies greatly from one region to another, for example, 160 species of birds are held by the forests of North America, while 130 species of birds are held by the Tropical Forests of Hawaii. The efforts to conserve an area's biodiversity is centred upon the endemic species of that area because the loss of 
those lead to a global loss of species diversity. Endangered species are also usually defined by the decrease in the number of endemic species [4].

\section{Approaches to Biodiversity Conservation}

The significance of biodiversity conservation efforts is explained and measured through different aspects such as conservation of species, maintenance of communities or sustainability of ecological function. These aspects are further briefly explained below [5].

\section{Specie Significance}

When allocating weights to the species significant for conservation efforts, all species do not carry equal weights necessarily and biosystematics provides various approaches to decide. The conservation value to species can be assigned through considering various approaches. One of this is that specie sharing similar genetic makeup, distributed geographically, would have lesser value, while those having distinct genetic makeup and spaced far away in geographical locations would have greater value. But on the other, considering the conservation efforts for an already protected species, the other species having a more similar genetic makeup would be more valued than those having differences in genetic makeup [5].

Moreover, the habitat, community, ecological and geographical conditions can be combined with the phylogenetic information of a specie to assign the value for conservation efforts. For instance, it can be inferred that a geographical location having lesser longbranch taxa will be lesser valuable for conservation efforts and vice versa. Therefore, there are various approaches, but not one, and the rationale of that condition and time are to be prioritized to decide [5].

\section{Geographic distribution}

Geographic distribution of a specie is yet another a considerable factor, to assign value for conservation efforts. A general rule followed is that the species that dispersed widely in a number of geographical locations are given less value whereas those concentrated in a specific region are given high value. Furthermore, among those species, which are concentrated in a certain geographical location, those having low population diversity are prioritized more rather than the endemic specie of that area since they are well in number in that area [5].

\section{One size fits all- Not so Relevant}

As discussed earlier, there is not one approach or standard relevant or enough to measure the value of species to be conserved. Thus, the scientific community has built five basic criterions to provide a reference for assigning biological value to species to be conserved [5].

- Richness is the first standard. Richness is defined by "the number of species or habitats in a given area". Richness can be relevant to the species as well as the geographical location. The general principle here is that a geographical location having greater species or habitats per unit area, is given high value rather than the geographical location which does not. Therefore, it can be observed that the dry forests having lesser specie richness and habitats is not on the priority lists for conservation rather, the tropical forests are [5]. 
- Endemism is the second standard. Endemism as described earlier is defined by "the narrowness of the distribution of the species in an area". A region having more endemic species, thus having specie richness, is given high value e.g. Madagascar constituting $80 \%$ of rare plant species [5].

- Rarity of species or habitat is the third standard. A geographical location having higher number of rare species or rare habitats is given greater value for conservation efforts rather than that having the specie which can be easily found elsewhere in the world. For example, wetlands in temperate region are not much of a concern, but wetlands in arid regions are considered valuable [5].

- Ecosystem services, is the fourth standard. Ecosystem services is defined as "the importance of the natural habitat, or resident single species capable of influencing ecosystem function for various services of importance to humans". Therefore, greater value is assigned to a forested watershed because of its usefulness to the general public as a source water [5].

- Protected status and representation are the last standard. It is defined by "the relative protection of the species or ecosystem that already exists". An area which has not been represented in a system of protected areas is prioritized more for conservation efforts rather than which is not [5].

\section{Innovations for Biodiversity Conservation in Universities}

Though humans are the initiators of this disaster, the foremost impact of this disaster is on humans as well. In accordance with this, it can be proposed that efforts and practices should be initiated from the students specially from university students, for the conservation of biodiversity. Our project focuses on three major propositions for ensuring innovations for biodiversity conservation in universities which are further explained below.

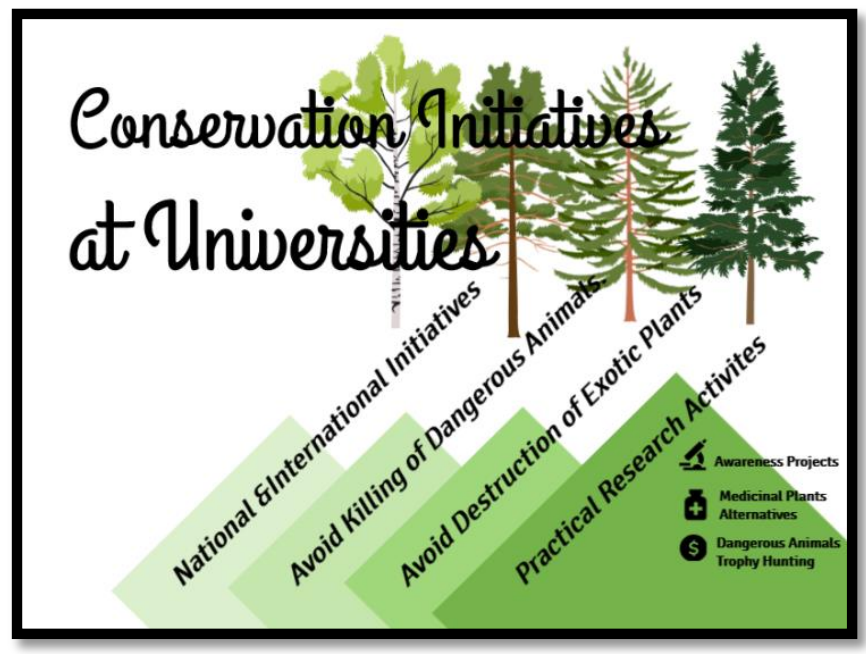

Figure 1 Figurative description of the proposed Conservation Initiatives that can be taken at University Level.

\section{Engagement of University students in National \& International Initiatives}

First domain to be covered is engagement of university students in national and 
international initiatives related to bio conservation. It is being proposed that the university students should be involved in the conservation initiatives being taken at national and international, since they have the exposure and ease of access to do so. They can take part in workshops, seminars, conferences highlighting the significance of conservation and raising awareness about it. Moreover, they can also take part in on-field activities related to conservation, since they are the educated lot of the nation, they can be easily trained to do so.

\section{Avoiding Killing of Dangerous Animals and Destruction of Economically Significant Plants}

Secondly, students could also be encouraged to create awareness among masses to avoid killing of animals for safety or excessive use of plants for economic benefits. Most of the endangered plants and animals are those, which apparently pose a threat to human life or are economically beneficial for them, thus humans either kill or exploit them for their safety and benefits. This needs to stop! Considering the endangered species from Pakistan, Common Leopard and Grizzly Black Bear are among them, their habitat is the Western Himalayan Eco-region of Pakistan and unfortunately the most common threat to these animals is killing by humans for safety. This human-wildlife conflict has led not only to their, but endangering of many other animals as well, so much that some may also have gone extinct. As far as the commercially or economically significant plants are concerned, the forest woods used for paper, fires and furniture, and the medicinal plants are the biggest examples of mass destruction of habitats and biodiversity by humans. Since these woods and logs are cut, they associated microbiota and animal species is also disrupted, hence the whole ecological cycle of that region. Therefore, university students, who have the power of knowledge, can use it to spread awareness to put an end to these activities.

\section{Practical Research Activities regarding Conservation}

At the end, students could be involved in practical research activities that have conservation as their primary focus, through credit hours, internships or thesis work. As discussed earlier, there are various reasons due to which humans engage in destruction activities. Thus, universities should take initiatives to allocate certain credit hours, scores or any other form of evaluation and bound the students to perform some level of conservation efforts. For example, as discussed earlier, most of the plants are being destroyed due to their medicinal usefulness, thus students in university levels, should be encouraged to make alternatives for this problem, by developing similar medicinal extracts so that the plants are not destroyed. This can be their final year research projects or group projects etc. Moreover, the community services and internships shall not be merely focused on human and technical centred activities, rather the universities shall also appoint the students in the organizations carrying conservation activities and should compel the students to perform hand on conservation and its awareness campaigns and drives.

\section{Conservation Initiatives taken at Capital University of Science \& Technology (CUST), Islamabad}

We do not believe in preaching only, but doing as well. Capital University of Science \& Technology, Islamabad has under taken various conservation activities including symbolic walks, seminars and research activities in this line. Moreover, the university has also formally established a Directorate for Sustainability and Environment (DSE) for the purpose of encouraging the students and providing them with opportunities to engage in 
conservation and sustainability of the environment. In addition to this, the university has also held meetings and is in talks with the renown organization WWF (World Wide Funds for nature), Pakistan and its Islamabad office to have a formal collaboration to provide human and other resources needed for conservation activities. In this line, CUST, Islamabad, also has its students working as students/youth ambassadors under the WWF, Youth Development Programme. Furthermore, CUST Islamabad also has its own FM radio channel, which has been actively utilised by DSE, CUST to spread awareness regarding this topic. CUST, Islamabad is still striving to improve and increase its part in the conservation efforts of the area and the conservation efforts being held all over in general, to play its role towards a safer and better environment.

\section{Conclusion}

It can be concluded from the discussion above, that conservation should be an integral policy or strategy for the nations and humans all over the world, since it is as much of a necessity for them and their safe and prosperous futures as any other material or capital wealth and strategies. Unfortunately, humans around the globe have only altered the ecosystems as per the benefits, not recognizing the harms of it on the other living communities in the planet and even its detrimental effects on humans in the longer run. Therefore, there is dire need for the masses to involve in and recognize the significance of conservation efforts. For this purpose, the universities and university students are the most optimum target, since they have the age, zeal, knowledge, resources and exposure to carry these activities them selves and also preach them to others. In this line we have advised three basic strategies which universities can carry to ensure the involvement of their students in conservation and environmental sustainability. CUST, Islamabad has also ensured the participation of the university and its students in the activities undertaken for the betterment of the environment and all living organisms.

\section{References}

1. I. R. (2001). Biodiversity, definition of. Encyclopedia of biodiversity, 1, 377-391.

2. Wilson, E. O. (1989). Threats to biodiversity. Scientific American, 261(3), 108-117.

3. Pihkala, P. (2018). ECO-ANXIETY, TRAGEDY, AND HOPE: PSYCHOLOGICAL AND SPIRITUAL DIMENSIONS Swingland OF CLIMATE CHANGE: with Karl E. Peters, "Living with the Wicked Problem of Climate Change"; Paul H. Carr, "What Is Climate Change Doing to Us and for Us?"; James Clement van Pelt, "Climate Change in Context: Stress, Shock, and the Crucible of Livingkind"; Robert S. Pickart, "Climate Change at High Latitudes: An Illuminating Example"; Emily E. Austin, "Soil Carbon Transformations"; David A. Larrabee, "Climate Change and Conflicting Future .... Zygon ${ }^{\circledR}, 53(2), 545-569$.

4. on Noneconomic, C., of Biodiversity, E. V., \& National Research Council. (1999). The Values of Biodiversity. In Perspectives on Biodiversity: Valuing Its Role in an Everchanging World. National Academies Press (US).

5. National Research Council. (1999). Perspectives on biodiversity: valuing its role in an everchanging world. National Academies Press 